\title{
O ESTATUTO DA FILOSOFIA NO ENSINO SECUNDÁRIO nO BRASIL DURANTe a DitadURA MILITAR
}

\author{
Celso João Carminati \\ (Universidade do Estado de Santa Catarina - Florianópolis - Brasil)
}

\section{Contexto social e político}

Os anos após o golpe militar de 01 de Abril de 1964 foram marcados por fortes medidas, tais como os Atos Institucionais (AI), que deram ao Presidente da República o direito de legislar no campo financeiro ou orçamentário, com a instituição do recurso do "decurso de prazo": os projetos considerados urgentes pelo Executivo eram automaticamente aprovados se o Congresso Nacional não os apreciasse em 30 dias. Ficou suspensa a imunidade parlamentar, eliminados os direitos civis de todo cidadão envolvido com práticas consideradas subversivas, etc. O AI-2 manteve as deliberações do decreto anterior, estabeleceu outras que ampliavam ainda mais os poderes do Presidente, tais como a decretação de estado de sítio; baixar decretos-leis complementares; decretar o recesso do Congresso Nacional, bem como das casas legislativas estaduais e municipais; o AI-3 veio em seguida a vitória da oposição nas eleições de 1965, onde instituíram a eleição indireta dos governadores pelas respectivas assembléias legislativas e transformou o mandato de prefeitos em cargo de confiança dos governadores.

As reações ao regime foram intensas, e os movimentos reivindicatórios, representaram um grande impulso nas suas organizações e mobilizações sociais. Diante desse quadro, durante os anos de 1967 e $1968^{1}$, as manifestações sociais se intensificaram,

1 O ano de 1968 foi marcado em nível mundial por grandes protestos de estudantes e de diversos movimentos da sociedade civil contra o "imperialismo", em defesa do Vietnã, etc... Sobre a realidade brasileira no ano de 1968, ver: Zuenir Ventura, 1968. O ano que não terminou. Rio de Janeiro, 1988.

Philosophica, 36, Lisboa, 2010, pp. 159-180 
"o movimento estudantil realizou grandes mobilizações contra o governo; o movimento sindical dos trabalhadores começou a sofrer um processo de renovação e de resistência à política econômica, culminando com as greves operárias de Contagem (MG) e Osasco (SP) em 1968; setores da Igreja Católica associaram-se à luta oposicionista; golpistas de primeira hora, como Carlos Lacerda - que em 1964 era governador da Guanabara - juntaram-se a políticos cassados pelo Regime, como Juscelino Kubitschek e o próprio João Goulart, e fundaram a Frente Ampla que objetivava aglutinar forças oposicionistas"”.

Porém, aos poucos o projeto econômico e político implantado pelos militares demonstrava-se mais contraditório, e os interesses dominantes das elites encontraram certa oposição. Anos mais tarde, as inquietações ${ }^{3}$ da sociedade civil repercutiram no Congresso Nacional e, no dia 13 de Dezembro de 1968, o Governo Costa e Silva, num ato de demonstração de força baixou o AI-5, confirmando a chamada "linha dura" nas diretrizes do governo e, assim, não permitindo que a sociedade avançasse nas suas reivindicações e conquistas. Foi instituída a Lei de Segurança Nacional ${ }^{4}$. A partir deste período se intensificaram as prisões, muitas de forma arbitrária, torturas e assassinatos ${ }^{5}$.

De acordo com VIEIRA, "a Lei de Segurança Nacional destruiu as liberdades públicas no Brasil, transformando-se em enérgico instrumento

2 GERMANO: 1993, p. 65.

3 Segundo VIEIRA (1985): "Os grupos de oposição foram-se unindo precariamente, atuando em grandes manifestações e passeatas de protesto nos anos de 1967 e 1968. O movimento estudantil, a ação dos trabalhadores e a Frente Ampla irromperam em diversos lugares do País. Opunham-se ao governo, tanto nas ruas, nos comícios e nas passeatas, quanto no Congresso Nacional..., registre-se também uma passeata no centro do Rio de Janeiro, reunindo cerca de cem mil pessoas. Os líderes oposicionistas nos sindicatos começaram uma luta para retomar os cargos eletivos dos sindicatos, então ocupados por interventores do governo. Em várias cidades, o movimento sindical deflagrou greves, paralisando importantes indústrias".

4 O Decreto Lei n. ${ }^{\circ} 314 / 1968$, tinha por objetivo identificar e eliminar os inimigos internos, quais sejam: todos aqueles que questionavam e criticavam o regime estabelecido pela ditadura militar.

5 Segundo Octavio Ianni, "toda brutalidade da dissociação entre o Governo e o povo, o Estado e o cidadão, a ditadura e o súdito, tudo isso estava cotidianamente realizado e recriado na repressão generalizada. A prisão, o sequestro, o sumiço, o assassinato político, junto com o arrocho salarial, a intervenção governamental nos sindicatos urbanos e rurais, a supressão das ligas camponesas, a manipulação do boato e o medo, como técnicas de poder, tudo isso configura uma realidade política fascista que se registra nas produções artísticas. Afinal, são muitos os mortos, assassinados e desaparecidos, os mortos sem sepultura: Olavo Hansen, José Porfírio, Manuel Fiel Filho, Santos Dias da Silva, Benedito Gonçalves, Orcílio Martins Gonçalves, Antônio Carlos Nogueira Cabral, Antônio Benetazzo, Rubens Paiva, Alexandre Vanucchi Leme, Wladimir Herzog, Osvaldo da Costa, entre muitos outros", IANNI: 1981, p. 177. 
de repressão política. Atacando os direitos individuais, na prática avançou contra os direitos de reunião, de associação e da imprensa"6.

Neste contexto, pela propaganda de "democracia e liberdade" prometidas durante o regime militar, o presidente Ernesto Geisel (1974-79) substituiu a ideologia da segurança nacional pela ideologia de integração nacional. Esta foi uma das estratégias de sobrevivência do regime militar, que resistiu por mais seis anos após seu mandato. O Presidente Ernesto Geisel falava em democracia, e viu-se obrigado a adotar a teoria da distensão ${ }^{7}$ e "abertura lenta e gradual" com o objetivo de aliviar as pressões da sociedade brasileira. Mesmo assim, manteve-se o A1-5, aprovou-se a Lei Falcão ${ }^{8}$, que determinava a forma como os candidatos aos cargos eletivos deveriam aparecer para o público, e o pacote de Abril de 1977, fechou o Congresso Nacional.

A propalada abertura política, veio acompanhada de pelo menos três medidas rígidas: a implantação do estado de sítio, as medidas de emergência e finalmente o estado de emergência. Em oposição aos Governos militares, somava-se, a Conferência Nacional dos Bispos do Brasil CNBB - a ordem dos Advogados do Brasil - OAB - a Associação Brasileira de Imprensa - ABI - os sindicatos, as associações de moradores, movimentos populares, associações de professores, profissionais liberais e a tantos outros que lutaram por estado de direito, democracia, liberdade, trabalho, moradia e justiça social.

O último Presidente militar foi João Batista Figueiredo (1979-1985). O mesmo falava em distensão, mas a maioria das reformas políticas de seu mandato teve sempre um caráter autoritário. Mesmo com a revogação do AI-5 e a concessão da anistia a todos os exilados políticos.

Já na década de 1980, o processo de relaxamento foi inevitável. A reforma partidária, por exemplo, possibilitou o uso da palavra "partido" para agremiações. No entanto, eram proibidos os partidos que se fundamentavam na fé religiosa, no racismo ou em sentimentos de classe social. Os senadores biônicos ${ }^{9}$ foram mantidos, pois os mesmos exerciam importantes funções a favor do governo no colégio eleitoral.

\footnotetext{
6 VIEIRA: 1985, p. 34.

7 Segundo VIEIRA (1987), o governo entendia a "distensão" como diminuição de pressão e seria feita em várias etapas, tais como a suspensão parcial da censura prévia, o estabelecimento de limites para o exercício dos direitos humanos, reformas eleitorais para melhorar o nível de representação política. A "distensão" estaria completa quando se revogasse o Ato Institucional n. ${ }^{\circ} 5$.

8 A designação lei Falcão", foi uma homenagem ao então Ministro da Justiça - Armando Falcão. Por suas regras, os partidos políticos só exporiam, no rádio e na televisão, sua denominação, o número e o currículo dos candidatos.

9 Ocupando um terço das vagas do Senado, este tipo de Senador não era eleito por voto popular, e sim por um colégio eleitoral.
} 
Indicativo desta situação foi a vitória do governo em apenas dois estados no ano de 1982 para as eleições de governadores. O movimento nacional pelas eleições diretas já foi frustrado pois a proposta foi rejeitada pelo Congresso, resultando na eleição de Tancredo Neves que veio a falecer em seguida, sem ter assumido a presidência, sendo empossado, o vice-presidente José Sarney. Será neste contexto que discutiremos a reforma educacional do ensino da educação primária e secundária, lei n. ${ }^{0} 5.692 / 71$, que retirou a Filosofia das escolas secundárias.

\section{Os caminhos da educação e as reformas}

As mudanças impostas pelo regime militar após 1964, tanto em nível econômico, quanto em nível político, exigiram a reformulação do sistema de ensino brasileiro, para atender às condições do projeto de desenvolvimento adotado.

No ano de 1964 técnicos do governo brasileiro, vinculados ao Ministério da Educação e Cultura - MEC e da United States Agency for International Development - USAID, constituíram uma comissão para celebrar um convênio de cooperação. A nomeação dessa comissão mista, entre americanos e brasileiros, foi uma resposta do governo às pressões sociais exercidas por estudantes, que reivindicavam reformas profundas nas universidades e no sistema de ensino em geral.

Em menos de dois meses, o trabalho da comissão ficou pronto e, assim, o governo de Artur da Costa e Silva (1967-1969) nomeou um grupo de trabalho com a tarefa de, em um mês, apresentar um projeto de lei para solucionar a crise da universidade brasileira. Assim, a reforma do ensino secundário ocorreu após as recomendações do Grupo de Trabalho da Reforma Universitária - GTRU de 1968, numa tentativa de resolver a procura dos estudantes por vagas nas universidades. Em decorrência disto, foram criados os cursos profissionalizantes obrigatórios para as escolas de ensino secundário atrelando os objetivos da educação escolar à formação de mão-de-obra para o mercado de trabalho.

Contudo, nem o modelo que modernizaria o sistema educacional brasileiro, nem as verbas externas foram suficientes para a implantação dos princípios contidos no plano de reforma do ensino. Com a reformulação do ensino secundário, as disciplinas da área de ciências humanas, passaram a ser excluídas do currículo. Submissos aos princípios da ideologia de segurança nacional e ao projeto de desenvolvimento implementado pelos militares, os currículos passaram a ser constituídos por um núcleo comum obrigatório em nível nacional, tendo por base as disciplinas Educação Moral e Cívica e Organização Social e Política do Brasil. Com esta medida, a disciplina de Filosofia ficou numa condição de abandono e quase extinção. 
Desse modo, à semelhança do ensino superior, o ensino secundário também foi direcionado por objetivos desenvolvimentistas. A introdução da profissionalização e a retirada de disciplinas humanísticas, como é o caso da Filosofia, teve como princípio a formação imediata da mão-de-obra para o mercado de trabalho, contendo, com isso, a demanda por vagas no ensino superior.

\section{A retirada da filosofia do currículo secundário}

Para melhor compreendermos como e por que a disciplina Filosofia foi retirada dos currículos do ensino secundário, é imprescindível recuar um pouco na história recente do país, no período que antecede o golpe militar de 1964; e para que esta discussão ganhe maior inteligibilidade, se faz necessário ouvir suas diversas vozes e tornar presente a correlação de forças do período estudado. É importante, considerando aquele contexto, conhecermos alguns princípios das reformas educacionais dentro do projeto de desenvolvimento adotado pelos militares, identificando algumas razões e conseqüências da sua retirada dos currículos escolares.

Decorrente de medidas autoritárias, a reforma educacional de 1971 definiu o papel do ensino secundário para atender as necessidades de formação de mão-de-obra. Os currículos foram organizados com disciplinas obrigatórias que constituíram o chamado núcleo comum, com Educação Moral e Cívica, Educação Física, Educação Artística e Programas de Saúde, estabelecido pelo Conselho Federal de Educação; a parte diversificada deveria atender às peculiaridades regionais e as disciplinas passaram a ser relacionadas pelos Conselhos Estaduais de Educação ou em algumas situações escolhidas pelos estabelecimentos de ensino.

Assim, a disciplina de Filosofia deixou de existir enquanto obrigatória, o que representou na prática o seu abandono, embora haja notícias de que algumas escolas a tenham mantido em seus currículos. Historicamente, o ensino de filosofia no II grau, sobretudo no século XX, tem oscilado de acordo com os interesses governamentais, ora presente, ora ausente. Segundo CARTOLANO (1985, p. 56),

"a reforma Capanema [Decreto-lei n. ${ }^{\circ} 4.244$, de 09 de Abril], instituída em 1942 (Lei Orgânica do Ensino Secundário), durante o Estado Novo, não mudou muito o panorama do ensino secundário no Brasil, que continuou a ser enciclopédico e elitista, devendo proporcionar cultura geral e humanística aos adolescentes que se preparavam para o ensino superior. $\mathrm{O}$ ensino secundário foi estruturado em dois ciclos: o ginásio, com duração de quatro anos, e o colégio que, com duração de três anos, compreendia dois cursos paralelos: o clássico, que enfatizava a formação intelectual, além de um panorâma do conhecimento de 
filosofia e um estudo das letras antigas; e no científico, a formação intelectual foi marcada por um estudo maior das ciências. $\mathrm{O}$ ensino da filosofia ocupou um maior espaço nos currículos dos cursos clássicos e científico, sendo ministrado como disciplina obrigatória na $2 .^{\mathrm{a}}$ e $3 .^{\mathrm{a}}$ séries daquele e na $3 .^{\mathrm{a}}$ série deste último. Mas a história da filosofia, que pela Reforma Campos [de 4-4-1932] estava presente no currículo do ciclo complementar para os cursos jurídicos, é deixada de lado por Capanema. [...] Já os programas de 1951, publicados pela Portaria n. ${ }^{\circ} 966$, de 02 de Outubro, elaborados pela congregação do colégio Pedro II, eram menos extensos, devendo, no entanto, ser claros e flexíveis. As aulas de filosofia foram, a princípio, distribuídas em quatro aulas por semana na $2 .^{a}$ série do clássico e $3^{\circ}$ científico e duas aulas semanais no $3^{\circ}$ clássico. [A partir da lei n. ${ }^{\circ} 4.024 / 61$ a presença da filosofia no currículo assim se justificava]: a filosofia constitui o complemento necessário à formação do espírito, como instrumento, que é, da grande arte do raciocínio. [...] A filosofia é aqui valorizada como necessária à medida que se apresenta como um instrumento da lógica, ou seja, da grande arte do raciocínio.”.

Outro aspecto que a lei da reforma de 1971 apresenta é a terminalidade, isto é, a proposta da substituição de um ensino preparatório para níveis superiores por uma estrutura que, como se vê no artigo $1^{\circ}$, visaria "propiciar ao educando a formação necessária ao desenvolvimento de suas potencialidades como elemento de auto realização, qualificação para o trabalho e preparo para o exercício consciente da cidadania" 10 .

Entre o explícito e o implícito do texto da lei, percebe-se que a reforma educacional de 1971 visava basicamente conter a demanda social por educação superior, através da 'terminalidade' embutida no texto legal.

O que se deve ressaltar é que, na reforma do ensino secundário de 1971, a função clássica e propedêutica foi menosprezada, passando a preponderar a formação profissionalizante. $\mathrm{Na}$ avaliação de CUNHA (1977), o governo fez a reforma, acreditando que a terminalidade, de um lado, daria a seus concluintes a garantia imediata de uma profissionalização e, de outro, evitaria a frustração provocada pela conseqüência do antigo ensino médio que centrava seus objetivos na formação clássica. $\mathrm{O}$ fim da frustração de quem não entraria na Universidade, seria possível mediante inserção no mercado de trabalho, justificando, assim, o ensino secundário profissionalizante para aqueles que não conseguissem ingressar nos cursos superiores.

Por sua vez, as reformas implantadas durante o regime militar devem ser compreendidas também, a partir de

10 Para saber mais sobre isto, ver: Ilza Rodrigues Jardim (Org). Ensino de $1^{\circ}$ e $2^{\circ}$ graus. Porto Alegre: Sagra, 1986. 
"uma nova teoria, a teoria do capital humano"1, que passou a enfatizar a relação entre a educação e o caráter mensurável do desenvolvimento. Vários autores ${ }^{12}$ apontaram para o fato de que o desenvolvimento nacional não seria apenas fruto dos recursos naturais, mas também e, sobretudo, dos recursos humanos que poderiam potencializar os recursos naturais. Assim, a educação assumiria papel capital ao suprir, homens e mulheres, crianças e adultos, dos conhecimentos que viriam a ampliar sua capacidade técnica e, por conseguinte, sua produtividade. Este seria o caráter do capital humano da educação"13.

Para sustentar a teoria do capital humano, o governo acreditava que as novas condições de produção exigissem maior grau de qualificação profissional, necessário para operar equipamentos sofisticados e para apresentar soluções criativas no contexto da empresa moderna. Dessa forma, o investimento em educação ${ }^{14}$ seria o responsável pelo aumento da produção como também dos rendimentos dos trabalhadores, desde que abdicassem de suas horas de lazer, em favor do treinamento e do estudo, podendo obter assim maiores rendimentos, e quem sabe, viessem a se tornar capitalistas.

Além disso, a teoria do capital humano reduz a concepção de educação na medida em que a enfoca apenas como fator econômico, isolando-a das questões políticas, sociais e filosóficas, e limitando, desse modo, a visão de educação às condições do mercado e do lucro. Portanto, parece-nos que a propagada visão utilitarista de educação, sobretudo a partir dos anos 1950 em toda a América Latina, base para as reformas educacionais no Brasil, dificultou a permanência do ensino de filosofia nos currículos de II grau, bem como a manutenção de outras disciplinas de caráter não profissionalizante. Assim, por não profissionalizar e por não ser útil à formação profissional, a filosofia perdeu qualquer lugar no ciclo médio.

11 A teoria do capital humano foi desenvolvida por autores norte-americanos no final dos anos 1950 e início dos anos 1960. Essa teoria, teve grande influência sobre a educação, uma vez que aposta na educação como solução para o desenvolvimento social. A teoria do capital humano atingiu seu apogeu no final dos anos 1970.

12 Ver por exemplo: Theodore Schultz. O Capital Humano. Rio de Janeiro: Zahar, 1973 e, do mesmo autor, O Valor Econômico da Educação. Rio de Janeiro: Zahar, 1967, ou Andrew Frank. "Human Capital and Economic Growth". In: Economic Development and Cultural Change (apud, NÓBREGA, 1995, p. 17).

13 NÓBREGA, 1995, p. 54.

14 De acordo com FRIGOTTO (1984, p. 40), “a educação, então, é o principal capital humano enquanto é concebida como produtora de capacidade de trabalho, potenciadora do fator trabalho. Neste sentido é um investimento como qualquer outro". 


\section{Retirada e regresso da filosofia - algumas discussões}

As razões da retirada da filosofia aqui brevemente discutidas, expressam as conexões entre o discurso político e ideológico, o implícito e explícito, tanto nas leis quanto nas ações dos governos militares. Os textos citados, escritos na sua maioria, no período que corresponde à luta pela reintrodução da filosofia no secundário, vêm alimentar nossa discussão, desafiando-nos a ouvir as diversas vozes daqueles envolvidos nesse processo. Assim, poderemos melhor apresentar algumas razões e conseqüências do seu afastamento.

O ensino de filosofia, na avaliação de BOSI (1983, p. 135), foi atacado pelas ações da tecnoburocracia, por sua condição de disciplina de caráter crítico. Segundo ele, a filosofia,

"desapareceu abruptamente dos cursos médios. Esta disciplina, cuja propriedade é a da reflexão crítica sobre a teoria e a prática, capaz de perscrutar a significação das ciências da natureza, das ciências do homem, o andamento da cultura e suas implicações ideológicas, é alijada no período crucial de formação do adolescente e, por motivos análogos, praticamente desaparece dos currículos superiores. [...] Aqui, o golpe do poder tecnoburocrático foi mais estrondoso e ostensivo do que em qualquer outro setor da educação superior brasileira." (grifos meus)

No debate sobre a importância do ensino de filosofia nos currículos secundário, PEGORARO (1979, p. 15) não hesitou em definir os motivos que levaram o regime militar a retirar a disciplina de filosofia das escolas secundárias. "Sem dúvida, a filosofia foi retirada por razões ideológicas e estratégicas inspiradas na segurança nacional. [...] A disciplina era considerada perigosa, pois poderia desviar a juventude do pensamento oficial".

Para estes autores, o projeto de profissionalização esteve intimamente ligado e submetido à necessidade de formação de mão-de-obra para o mercado. O princípio de segurança nacional passou a vigorar como estratégia ideológica, valendo como instrumento de defesa das classes hegemônicas no poder, contra os inimigos internos tais como intelectuais, políticos, artistas e líderes populares. Cassando o inimigo interno, o discurso oficial dos governos militares utilizou como propaganda a concepção de unificação do Estado nacional, criando no imaginário da população a idéia de que a nação é indivisa ${ }^{15}$.

15 De acordo com CHAUÍ, "não é por obra do acaso, mas por necessidade, que o discurso do poder é o do Estado nacional, pois a ideologia nacionalista é o instrumento poderoso da unificação social, não só porque fornece a ilusão da comunidade indivisa (a nação), mas também porque permite colocar a divisão fora do campo nacional (isto é, na nação estrangeira)" (CHAUÍ, 1993, p. 21). 
Na mesma perspectiva apresentada por Pegoraro, observamos a preocupação de VALLS (1983, p. 42), que ao discutir esta temática, afirma, que "a Filosofia, principalmente na segunda metade dos anos 1960, tornou-se indesejável, passou a ser considerada perniciosa, subversiva. Há dois mil anos, Sócrates foi condenado à morte como sedutor da juventude e inimigo dos deuses do Estado".

Assim, tudo leva a crer que a rejeição à filosofia e seu ensino se configurou numa rejeição aos produtores de suas idéias, quais sejam seus próprios professores, principalmente aqueles que lecionavam nas universidades brasileiras. Muitos deles foram proibidos de exercer sua função de pensadores, tanto em salas de aula, quanto na sociedade de modo geral.

Também RODHEN (1980, p. 8) tem se pronunciado sobre isto, pois segundo ele, "o Estado tem medo de homens que fazem verdadeira filosofia. Tais homens, pela sua própria estatura de pensamento e de homens, não servem ao Estado, e ele não os favorecerá. [...] Entre nós não aconteceu justamente isto, que o Estado se desfez dos seus melhores elementos, daqueles em quem não podia confiar?"16.

Dessa maneira, embora se referindo ao conjunto das ações dos professores universitários, PEGORARO (1979, p. 13), continua, "quando um professor enveredar para a análise das causas próximas, dos problemas que nos circundam; quando se interroga sobre a justiça, a eticidade do regime, o absurdo, a miséria, da doença e da fome produzidos pelos sistemas; quando um professor tratar destas causas próximas, cai na desgraça oficial e na mira dos chefes de departamentos.

Referindo-se a tal situação, VALLS afirma que: "no passado recente brasileiro, os professores mais brilhantes foram aposentados ou expurgados das universidades, o pensamento crítico foi perseguido e desestimulado, o pensamento dogmático, representante do arbítrio, instalou-se nas escolas" (op. cit., p. 42).

No contraponto desta discussão, se apresentam representantes do movimento dos filósofos católicos, cujo presidente, Tarcísio M. Padilha ${ }^{17}$, atribuía o afastamento do ensino de Filosofia à "pouca seriedade" com

16 "Não é de se esperar nem também de desejar que os reis filosofem ou que os filósofos se tornem reis, porque a posse do poder prejudica inevitavelmente o livre juízo da razão. É imprescindível, porém, para ambos que os reis ou os povos soberanos (que se governam a si mesmos segundo as leis da igualdade) não deixem desaparecer ou emudecer a classe dos filósofos, mas os deixem falar publicamente para a elucidação dos seus assuntos, pois a classe dos filósofos, incapaz de formar bandos e alianças de clube pela sua própria natureza, não é suspeita da deformação de uma propaganda." (I. Kant, Sobre a paz perpétua - 1795).

17 Tarcísio Padilha foi presidente da Associação dos Filósofos Católicos, com sede no Rio de Janeiro. 
que professores e alunos tratavam os conteúdos filosóficos. Este argumento, ao invés de contribuir para o retorno da filosofia - princípio de que afirmava ser defensor - pelo contrário, reforçou a tese daqueles que queriam vê-la afastada do currículo.

De fato, sua afirmação toma o particular como geral: uma vez existindo deficiências na qualidade do ensino de filosofia, os seus professores não poderiam ser vistos isoladamente enquanto responsáveis por tal realidade, mas devem ser compreendidas no contexto e conjuntura da sociedade brasileira daquele período. Trata-se, antes de tudo, de analisar um contexto cujas imposições legais pretenderam impôr à força os objetivos do projeto desenvolvimentista.

\subsection{A luta pelo regresso da filosofia - a sociedade de estudos e atividades filosóficos - SEAF}

A SEAF foi fundada no dia 10 de Julho de 1976, na cidade do Rio de Janeiro ${ }^{18}$. De acordo com as declarações do professor Pegoraro, a SE$\mathrm{AF}$

"surgiu da preocupação que vivíamos em 1975-76. A censura e o burocratismo cego dominavam também o meio universitário. Isto gerava profundo desânimo entre professores e alunos. Todo projeto aberto esbarrava em entraves intransponíveis. O silêncio e o isolamento tiveram como conseqüência principal a improdutividade e a queda de nível, notadamente no âmbito dos Departamentos de Filosofia que sofreram censura mais forte." 19 .

De acordo com a ata da assembléia geral de constituição da sociedade, registrada no Cartório Civil de Pessoas Jurídicas Castro Menezes, (Avenida Franklin Roosevelt, $126-2^{\circ}$ andar salas 205/07 - Rio de Janeiro), sob o n. ${ }^{\circ} 44.980$, no livro A-12 de 02 de Dezembro de 1976, a assembléia dos fundadores da SEAF ocorreu dia 10/07/76 às 14:00 h na

18 Os seus fundadores foram: Olinto Antônio Pegoraro (Universidade Federal do Rio de Janeiro), Leda Miranda Hühne (Universidade Santa Úrsula), Maria Célia Simon (Universidade Santa Úrsula), Valério Rodhen (Universidade Federal do Rio Grande do Sul), José Anchieta Corrêa (Universidade Federal de Minas Gerais), José Henrique Santos (Universidade Federal de Minas Gerais), José Sotero Caio (Universidade Federal do Rio de Janeiro), Hílton Ferreira Japiassú (Universidade Federal do Rio de Janeiro e Pontifícia Universidade Católica do Rio de Janeiro), Antônio Rezende (Universidade Católica do Rio de Janeiro), Francimar Arruda Campos (Universidade Santa Úrsula), Ana Maria Garcia (Universidade Santa Úrsula) e Walter José Evangelista (Universidade Federal de Minas Gerais).

19 PEGORARO, 1981, p. 1. 
Estrada Velha da Tijuca n. $^{\circ} 45$, sala 5, na cidade do Rio de Janeiro ${ }^{20}$ e assim deliberou:

"A SEAF será uma sociedade civil, sem fins lucrativos e sem intuitos políticos, com objetivo principal de melhoria de condições para o estudo e a pesquisa de assuntos filosóficos; a divulgação de trabalhos filosóficos, por veículo próprio ou em cooperação com outros órgãos; o aperfeiçoamento do ensino de filosofia; a promoção do relacionamento interdisciplinar e o intercâmbio de idéias entre seus associados" 21 .

Ao longo de sua história, a SEAF tratou nos seus seminários e conferências de uma diversidade de temáticas. Suas preocupações não se voltaram apenas para os problemas específicos da filosofia, mas estavam relacionadas aos problemas da sociedade de forma geral e isto vem confirmar a idéia inicial de uma sociedade que transcendesse os muros universitários.

No dia 22 de Outubro de 1977, a SEAF realizou no Colégio São Vicente de Paula, também no Rio de Janeiro, o ciclo de conferências intitulado "Filosofia e Educação". O debate girou em torno das ações do regime militar na área educacional. Um dos temas foi a realidade do ensino de filosofia. Eis os temas abordados e seus respectivos palestrantes: "Política Educacional no Brasil" - Luiz Antônio Cunha, "O Ensino da Filosofia" - Marilena Chauí e "Estado e Educação do Povo" - Darcy Ribeiro.

O evento acima, repercutiu na imprensa e nos meios acadêmicos, suscitando o debate sobre o regresso da filosofia nas escolas secundárias, como pode ser percebido em artigo de Olinto Pegoraro, publicado no jornal $O$ Globo de 25/11/77, com título: "A Filosofia tenta provar que não está morta. Como? Voltando ao II grau":

"Não se postula um simples decreto, impondo aos colégios a matéria filosófica. O problema é mais amplo e estrutural. O problema do retorno da filosofia não se resolve a partir dele mesmo. [...] Mas com tal decreto arriscaríamos voltar a um ensino que se satisfaz com a transmissão de um saber acumulado, nas bibliotecas, livros e manuais. Um saber acrítico, meramente informativo e descritivo." 22 .

No mesmo ano, a revista Reflexão (PUCAMP - SP) ${ }^{23}$ publicou um

$20 \mathrm{O}$ endereço que aparece na ata de fundação, coincidia na época com o endereço da casa do professor Olinto Pegoraro, um de seus fundadores e primeiro presidente.

21 Ata e estatuto de constituição da SEAF, registrados no dia 02 de Dezembro de 1976.

22 PEGORARO, 1977, p. 2.

23 A revista Reflexão da PUC de Campinas - SP, publicou durante muito tempo, textos, artigos e documentos de membros da SEAF. 
pronunciamento da SEAF em que apresenta sua postura a favor do retorno do ensino de filosofia ao II grau, em defesa das disciplinas de ciências humanas e em defesa do mercado de trabalho para os formados em Filosofia. $\mathrm{O}$ referido documento não poupa críticas ao regime militar, dado que para o governo, "a prioridade do ensino fixa-se, portanto, em disciplinas que 'instrumentalizam' o aluno para o trabalho técnico". Diante das novas exigências do mercado de trabalho, a SEAF defendeu que,

"é justamente nesse processo tecnocrático que o ensino da filosofia se faz necessário. Sendo uma disciplina inteiramente 'formadora' e não 'instrumentalizadora', ela tem na formação do aluno um papel importante a desempenhar, pois funciona ou como estimuladora direta no campo das ciências humanas, ou como generalizadora e orientadora na opção do adolescente nas ciências propriamente técnicas." ${ }^{24}$.

Os anos seguintes, foram marcados por eventos no Rio de Janeiro, e em outras cidades brasileiras, pelo lançamento do Boletim da SEAF, dos Cadernos SEAF, publicados nas regiões em que havia núcleos em funcionamento, tais como São Paulo, Curitiba, Porto Alegre, Belo Horizonte, Belém e Florianópolis. A conferência realizada no Rio de Janeiro, no Colégio São Vicente de Paulo, foi, segundo nossa pesquisa, o primeiro debate público promovido pela SEAF sobre o "Ensino de Filosofia"25. Embora no seu momento inicial a SEAF estivesse mais preocupada com a realização de discussões sobre temas filosóficos e com a organização de grandes eventos, a questão do ensino de filosofia vai aparecendo como uma das suas preocupações centrais. Mas essa temática começou a ganhar maior importância a partir do segundo mandato de Olinto Pegoraro e Leda Hühne na diretoria nacional (1978-1980) e da organização dos núcleos regionais no final da década de 1970 e início da década de 1980. A partir desse período, o regresso do ensino de filosofia no II grau foi se tornando uma das principais bandeiras de luta da SEAF.

24 SEAF, 1977, p. 471.

25 Gostaria de lembrar que nesse mesmo ano a Sociedade Brasileira de Cultura Convívium realizou de 26 a 29 de Outubro de 1978 um encontro em São Paulo, onde se discutiu também "o ensino de filosofia no Brasil" e uma palestra sobre o ensino de filosofia no II grau foi proferida pelo professor João Paulo Monteiro - USP. O motivo, ou a razão desse encontro foi o lançamento dos três volumes da obra As idéias Filosóficas no Brasil", organizada por Adolpho Crippa e publicada pela editora Convívio de São Paulo. 
Em Fevereiro de $1979^{26}$ foi publicado o número 2 dos Cadernos SE$A F$. Na abertura, lêem-se dois documentos assinados pela SEAF e que definem sua posição sobre "A Crise da PUC" 27 e sobre a "Anistia". A SEAF, reunida em assembléia geral extraordinária realizada por ocasião da $31 .^{\text {a }}$ reunião anual da SBPC, em Fortaleza (CE), da qual participaram professores e alunos das diversas regiões do país, sentiu-se na obrigação de tomar uma posição face ao projeto governamental de Anistia:

“ANISTIA para todos os cidadãos atingidos pelo arbítrio [...]. O atual projeto de anistia, em tramitação no Congresso, é tímido e injustamente restrito. Ignora que 10 anos atrás a Nação vivia num clima de violência geral criado pelo Estado Totalitário. [...] A SEAF espera, pois, que o Congresso Nacional se coloque à altura do momento histórico e exerça a autonomia que o povo lhe outorgou, emendando o atual projeto, tornando-o irrestritamente abrangente" 28 .

A SEAF pronunciou-se também publicamente, contra a campanha difamatória e as acusações ao Pe. Henrique Lima Vaz e à Pontifícia Universidade Católica do Rio de Janeiro, notadamente ao seu Departamento de Filosofia ${ }^{29}$. O apoio ao padre Vaz e àquele Departamento de Filosofia foi importante na hora em que tendências fascistas se insurgiram contra o pensamento. Apesar dessa situação, segundo Pegoraro, em 1979, a famosa "crise" da PUC teve o mérito de suscitar novo interesse pela filosofia e projetou a SEAF no cenário cultural nacional.

O Conselho Editorial dos Cadernos era formado por Benedito Nunes, Henrique Cláudio de Lima Vaz, Hilton Ferreira Japiassú, Jean Ladrière, José Arthur Giannotti, Marilena Chauí e Raul F. Landim Francisco. Apresentam um pequeno histórico de sua fundação, os seus objetivos

26 Importa mencionar que o ano de 1979 foi, sobretudo para os trabalhadores rurais, operários e setores do campo popular progressista, o início de um momento de mobilização e organização. Em escolas e universidades, os professores se mobilizaram, fizeram greves, protestaram contra os baixos salários, contra o autoritarismo e contra a política educacional do regime militar.

27 Sabe-se que a "crise da PUC" teve origem no Departamento de Filosofia, em decorrência da demissão de ma professora de Filosofia pelo então chefe de Departamento.

28 SEAF, 1979, pp. 3-6. Os textos publicados no segundo número dos Cadernos SEAF são: "Do biênio vermelho a livorno: L'ordine nuovo" - Edmundo Fernandes Dias; "Psicanálise e arte" - Gerd Bornheim; "Ciência e anticiência" - Jean Ladrière; "Notas para um projeto de crítica ideológica ou de história crítica do pensamento" - Luiz Eduardo Bicca; "Verdade e libertação - uma questão epistemológica?" - Valério Rodhen; "Significação e ato ilocucionário" - Vera Cristina de Andrade Bueno; "A filosofia fácil: um ajuste de contas com a filosofia científica" - Wilson Mendonça.

29 A resposta do Pe. Henrique Vaz foi publicada com o título a "Crise da PUC: descen-

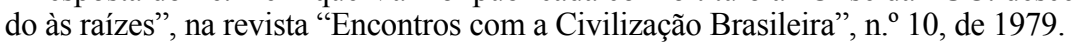


e uma concepção de filosofia. Afirmam neste editorial que "a filosofia - é o que se pensa - é uma atividade teórica duvidosa, desprovida de eficácia e relevância social, um adorno cultural supérfluo para uma sociedade voltada para os problemas mais urgentes do desenvolvimento econômico capitalista. Mas ainda, não só é acusada de duvidosa, supérflua, ineficaz e impotente, mas tomam-se os devidos cuidados para que ela assim permaneça". [E, continua o editorial]: sem privilegiar nenhuma corrente filosófica, política ou religiosa em especial, os cadernos SEAF se propõem a ser um veículo de livre manifestação de um pensamento filosófico que se queira responsável e criticamente engajado ${ }^{30}$.

O Jornal Correio do Povo - Caderno de Sábado - Porto alegre (RS) de 06/10/79, publicou alguns textos de professores de filosofia, sendo alguns deles sócios da SEAF. São eles: "Quem tem medo da filosofia?" Valério Rodhen; ${ }^{31}$ "Política da filosofia no Brasil" - Olinto A. Pegoraro ${ }^{32}$ e "Ser e não ser professor de filosofia" de José Arthur Giannotti.

Também nesse mesmo ano ${ }^{33}$, o Departamento de Filosofia da USP e a SEAF-SP organizaram duas mesas redondas sobre filosofia. A primeira sob o título "A filosofia no Brasil", com participação dos professores Bento Prado Júnior, Caio Navarro e Roberto Schwartz e a segunda sob o título "Ensino da filosofia no Brasil", com os professores José Arthur Giannotti, Renato Janine Ribeiro, Dermeval Saviani e os alunos de graduação Azildo Souza Campos e Rosely Roth. Nesse encontro apenas o

30 SEAF, 1979, p. 1. Os textos publicados no primeiro número, com exceção do último, foram originalmente apresentados em ciclos de conferências organizados pela SEAF-Rio: Henrique Cláudio de Lima Vaz - "Filosofia no Brasil, Hoje"; Marilena Chauí - "Crítica e Ideologia"; José Arthur Giannotti - "Cuidando de Filosofia"; Hilton F. Japiassú - "O Problema Epistemológico da Verdade"; Walter José Evangelista - "Dialética e Sociedade"; Olinto Pegoraro - "Historicidade da Existência"; Guido Antônio de Almeida - "Aspectos da Filosofia da Linguagem".

31 Segundo o autor, "O Estado tem medo de homens que fazem verdadeira filosofia [...] o Estado só favorecerá filósofos dos quais não tem medo [...] e, se alguém suporta ser filósofo em função do Estado, tem também de suportar ser considerado por ele como se tivesse renunciado a perseguir a verdade em todos os seus escaninhos", (o texto integral foi apresentado em 12 de Julho de 1979 na mesa-redonda "Dilemas da Produção Filosófica no Brasil", em Fortaleza, Ceará, como parte integrante do tema central da 31. . Reunião Anual da SBPC).

$32 \mathrm{O}$ autor chama atenção ao fato de que "todo o ensino deve ser crítico. A Geografia, a História, a Filosofia, enfim todas as disciplinas devem orientar o aluno a uma postura pessoal, a uma visão ampla e crítica das coisas que estuda. Não interessa quanto aprende mas como aprende, com que mentalidade e com que perspectivas o jovem termina seu curso".

33 Nesse ano também, o Deputado do PMDB Mauro Bragnato apresentou projeto de lei na Assembléia Legislativa, para a introdução da Filosofia ao II grau no estado de São Paulo. Em virtude da sua não aprovação, o mesmo Deputado reapresentou o projeto em 1982, mas com algumas alterações, tendo sido rejeitado outra vez. 
professor Giannotti se pronunciou contra a reintrodução da filosofia no II grau $^{34}$, alegando a inexistência de professores devidamente capacitados para lecionar a disciplina ${ }^{35}$. Ele manifestou-se "contrário ao retorno da filosofia ao II grau por acreditar que não existiriam professores capacitados em número suficiente para atender a demanda [...]. De que adiantaria ensinar filosofia no secundário com esse quadro? Serei a favor quando houver uma reforma".

A partir de 1981, houve uma importante mobilização organizada pelo prof. Olinto Pegoraro em torno dos Departamentos de Filosofia. Foram organizados os Encontros Nacionais do Departamentos de Filosofia. A realização do I ENDF, no Rio de Janeiro repercutiu muito na imprensa e por conseqüência na Secretaria de Educação Superior do Ministério da Educação que em uma de suas ações nomeou uma comissão de consultores para discutir a filosofia no secundário.

O trabalho resultou no texto final conhecido como o "Documento de Brasília”, que propunha: "a) a compreensão da filosofia como reflexão sobre a realidade vivida pelos adolescentes em sua articulação com as questões sociais, políticas, científicas e artísticas do presente; b) o entendimento da filosofia também como colaboradora no ato de repensar a tarefa pedagógica, em seu sentido amplo; c) utilizar o espaço que, legalmente, já foi reconhecido à filosofia, mas que na prática, não tem sido necessariamente ocupado; c) utilizar o espaço que, legalmente, já tem sido necessariamente ocupado; d) formar comissões de visitas e contatos com as escolas, com a finalidade de assessoria a reintegração e retorno da Filosofia a tais instituições de ensino" 36 . Porém, como o documento foi distribuído à imprensa, a reação às suas diretrizes correram logo e por isto não houve avanço nas discussões.

A revista Debates Filosóficos n. ${ }^{\circ}$ 2, publicada em Junho de 1981, trouxe a público os trabalhos apresentados no IV Simpósio Nacional da SEAF, assim como as principais conferências pronunciadas na $32 .{ }^{a}$ Reunião Anual da $\mathrm{SBPC}^{37}$. Vejamos os textos apresentados e seus respectivos

34 Outra declaração do professor foi publicada anos mais tarde: Segundo ele: "sempre tive muitas dúvidas a respeito de transformar filosofia em disciplina obrigatória no II grau" (Giannotti, apud, Folha de São Paulo, 1994, p. 6).

35 Ver a esse respeito: "Mesas - redondas de Filosofia". Folha de São Paulo, $18 / 03 / 79$, p. 3 .

36 Segundo relatório da Coordenação dos ENDF, o DOCUMENTO DE BRASÍLIA se apóia substancialmente nas diretrizes emanadas do I Encontro Nacional dos Departamentos de Filosofia, assim como nas concepções da SEAF.

37 Os Debates Filosóficos, ano 1, n. ${ }^{\circ} 1$ foi datilografado e editado como apostila. Infelizmente não encontramos nenhuma cópia. Mesmo assim, obtivemos informações que o texto "Graduação e Pós-graduação em Filosofia" da professora Marilena Chauí foi ali publicado. 
autores: "Identidade da SEAF" - Olinto Antônio Pegoraro; "Análise de diversas perversões" - Ernildo Stein; "Filosofia prática, sua relevância e atualidade" - Valério Rodhen; "Ideologias autoritárias e filosofia" - Marilena de Souza Chauí; "O ensino da filosofia no II grau: crítica ou alienação?" - Maria Célia Moraes Neiva Simon; "Recuperação da memória do ensino da filosofia no II grau" - Antônio de Rezende Silva; "Filosofia como resposta e filosofia como questão" - Maria do Carmo Bittencourt de Faria e "Filosofia e ciência" - Alberto Oliva.

Também nesse ano a revista Discurso, ${ }^{\circ} 12$ do Departamento de Filosofia da FFLCH da USP publicou um artigo da professora Marilena Chauí intitulado: "Quem são os amigos da Filosofia". Esse artigo é fruto de uma exposição feita no Encontro Nacional de Professores e Estudantes de Filosofia ${ }^{38}$.

Nesse artigo Marilena Chauí, se referindo ao ensino de filosofia no II grau, afirma que, "não apenas nós, da SEAF temos discutido o assunto, Convivium também o fez...". Contudo, ela faz uma crítica às concepções de filosofia lá discutidas, sobretudo, as apresentadas pelos professores G. Gusdosf, Creusa Capalbo e Tarcísio Padilha. O primeiro defende uma concepção de filosofia como "rainha das ciências", a segunda acreditava no papel do "Estado em revalorizar a filosofia", enquanto o terceiro parece propor "como forma de retorno da filosofia ao secundário, sua inclusão no curso de Educação Moral e Cívica". (CHAUÍ, 1980, p. 127).

No mesmo ano de 1981, ocorreram diversos encontros regionais sobre o ensino de filosofia no II grau. Segundo Pegoraro, "importantes eventos aconteceram em Mossoró, Natal (RN) Teresina (PI), Belém (PA), Manaus (AM), Belo Horizonte (MG), Santa Maria e Porto Alegre (RS), São Luís (MA), e Fortaleza (CE)"39.

Embora diversos núcleos estivessem organizados, o "momento mais importante da SEAF nesse período foi na UFMG - Belo Horizonte. O professor José Henrique dos Santos era reitor e o professor Anchieta era Chefe do Departamento de Filosofia e presidente da SEAF. Lá realmente tivemos apoio institucional à SEAF. Naquele momento foi possível a realização de um grande congresso ${ }^{40}$, com apoio do Conselho Nacional de Desenvolvimento Científico e Tecnológico - CNPq e da Coordenação de Aperfeiçoamento de Pessoal de Nível Superior - CAPES, junto com o Departamento de Filosofia" (2).

$38 \mathrm{O}$ evento foi promovido pela SEAF em Belo Horizonte no ano de 1979.

39 Infelizmente não será possível relatarmos as atividades dos diversos núcleos regionais da SEAF. Optamos em nossa pesquisa pelos regionais que sediaram a SEAF nacional.

40 O congresso acima referido foi o V Simpósio Nacional da SEAF realizado de 3 a 7 de novembro de 1981, na Faculdade de Direito da UFMG, Belo Horizonte. 
Após longas discussões, somente no ano de 1982, a Câmara de Ensino do Ministério da educação aprovou alterações na lei n. ${ }^{\circ}$ 5692/71, que desobriga os alunos de II grau a freqüentarem os cursos profissionalizantes, eliminando, na forma da lei, a dicotomia entre "educação especial" e "educação geral". De certa forma, a alteração da obrigatoriedade na profissionalização do ensino secundário não representou muitos avanços para o movimento que lutava pelo retorno da filosofia como disciplina obrigatória, pois à filosofia restou o lugar de disciplina optativa nos estabelecimentos de ensino, cabendo à vontade de diretores de escolas a sua presença nos currículos ${ }^{41}$.

\section{Aspectos da realidade da filosofia após os anos de 1980}

A lei n. ${ }^{\circ} 7.044 / 82$ que alterou dispositivos de alguns artigos da LDB n. ${ }^{\circ} 5692 / 71$, flexibilizou a formação e estrutura de atendimento e oferta do ensino, permitindo certa autonomia aos estabelecimentos escolares. Foi nesta perspectiva que a disciplina começou a ser oferecida em algumas escolas no país. Embora não faça menção direta a inclusão de disciplinas como Filosofia e Sociologia, muitos diretores de escolas se valeram da abertura concedida no artigo $4^{\circ}$ da lei de 1982 para iniciarem um movimento pela oferta opcional das disciplinas nas escolas de II grau. Eis o que nos diz o artigo $4^{\circ}$ : "Os currículos do ensino de $1^{\circ}$ e $2^{\circ}$ graus terão um núcleo comum, obrigatório em âmbito nacional, e uma parte diversificada para atender, conforme as necessidades e possibilidades concretas, às peculiaridades locais, aos planos dos estabelecimentos de ensino e às diferenças individuais dos alunos". Dessa forma, elas passaram a ser oferecidas na parte diversificada do currículo e com isto a formação dos alunos pode ter conteúdos humanísticos.

Um movimento de educadores, principalmente entre aqueles ligados à área da Pedagogia, durante e após o período da ditadura militar, vem realizando importantes discussões sobre a educação no Brasil, sobretudo diante da desatenção de muitos deputados constituintes para com a área educacional, quando da elaboração da nova Constituição. As discussões realizadas na cidade de Porto Alegre - RS, em 1988, pela Associação Nacional de Pós-graduação e Pesquisa em Educação (ANPED), foram importantes para que se pensasse um projeto nacional para a educação. Tais discussões impulsionaram o início dos trabalhos para uma "nova" LDB. O projeto n. ${ }^{\circ} 1258$ - c/88, com origem na Câmara dos Deputados, foi uma iniciativa conjunta do Fórum Nacional em Defesa da Escola Pú-

41 Foi nesse ano também, que o Deputado Estadual Mauro Bragnato reapresentou o projeto de reintrodução da Filosofia ao II grau no Estado de São Paulo, enquanto disciplina obrigatória, tendo sido vetado pelo então governador Paulo Maluf. 
blica, dos deputados de oposição, além de um acordo suprapartidário entre diversos Deputados Federais. Porém, entre muitas discussões, redações, negociações, emendas, com vários avanços e também retrocessos, a esperada LDB somente foi votada e aprovada na Câmara dos Deputados, no ano de 1993. No referido projeto, em seu artigo 48, inciso IV, o texto aprovado contemplava a inclusão das disciplinas Filosofia e Sociologia como obrigatórias nos currículos de II grau, hoje ensino médio.

Parecia consenso, na Câmara dos Deputados, a permanência da disciplina Filosofia no ensino médio, porém, o governo se rearticulou e apresentou um outro projeto com origem no Senado Federal. Ele foi apresentado pelo Senador Darci Ribeiro (PDT-RJ), em substituição, àquele aprovado anteriormente. Esse seu projeto $\mathrm{n}^{\circ} 1258-\mathrm{d} / 95 \mathrm{nem}$ sequer fez menção à Filosofia e, uma vez aprovado no Senado, retornou à Câmara dos Deputados, tendo como relator o Deputado Federal José Jorge do PFL - Pernambuco. Na Câmara, diante da pressão de vários setores, inclusive do Fórum Nacional em Defesa da Escola Pública, o projeto recebeu várias emendas antes de ser aprovado.

Para surpresa geral e decepção nossa, na Lei de Diretrizes e Bases da Educação Nacional, n. ${ }^{\circ}$ 9.394, aprovada e promulgada em 1996, a Filosofia ficou excluída dos currículos como se observa no artigo $36 \S 1^{\circ}$, inciso III. O texto enfatiza apenas que, ao final do ensino médio, os educandos devem demonstrar "o domínio dos conhecimentos de Filosofia e de Sociologia necessários ao exercício da cidadania"42, mas sem dizer que isto poderia se dar com a reintrodução da disciplina.

Nas Diretrizes Curriculares Nacionais para o ensino médio de 1998, a Câmara de Educação Básica, através da resolução n. ${ }^{\circ}$ 3/98, define no artigo 10 , inciso III, $\S 2^{\circ}$, alínea b, que as propostas pedagógicas das escolas deverão assegurar tratamento interdisciplinar e contextualização para os "conhecimentos de filosofia e sociologia necessários ao exercício da cidadania" (HORN, 2000, p. 196). Segundo este autor, esta "lei não caracterizou objetivamente sua obrigatoriedade no currículo, ficando novamente na condição de disciplina complementar, podendo ser ofertada ou não pela direção da escola dentro do quadro de preenchimento de $25 \%$ com disciplinas optativas" (Ibid.).

De acordo com a redação do texto da lei, esta disciplina foi incluída explicitamente no currículo de ensino médio. Na prática, contudo, por sua histórica presença no currículo, mesmo facultativa e em decorrência das lutas dos movimentos pela sua reintrodução nas escolas de ensino médio, observa-se ainda que lentamente, um aumento de sua presença nas escolas em diversos Estados da Federação brasileira.

42 Lei de Diretrizes e Bases da Educação Nacional. CNTE, ano II, n. ${ }^{\circ}$ 3, Março de 1997. 
Numa tentativa de implementar a sua introdução obrigatória no ensino secundário, o Deputado Federal, Padre Roque Zimmermann (PT/PR), apresentou à Câmara dos Deputados o projeto de lei n. ${ }^{\circ} 3.178 / 97$, que expressou a síntese de diversos esforços de professores e entidades na luta pela alteração do artigo 36 da lei n. ${ }^{\circ} 9.394 / 96$. O projeto tramitou no Congresso Nacional desde 1997 e foi aprovado pela Comissão de Constituição e Justiça, no dia 22 de Setembro de 1999. No Senado, embora não tivesse o mesmo consenso da Câmara, o projeto foi igualmente aprovado, porém, por recomendação pelo então Ministro da Educação ${ }^{43}$, em 8 de Outubro de 2001, o mesmo foi vetado pelo Presidente da República, Fernando Henrique Cardoso, que alegou "não haver professores suficientes formados para lecionar" 44 . Com certeza, os motivos devem ser outros, pois, de acordo com ALVES (2002, p. 141), as informações oficiais do Ministério da Educação, destacam que existia naquele ano no Brasil, 95 cursos de Filosofia reconhecidos, entre bacharelados e licenciaturas, e todos estavam formando professores.

Movimento parecido ocorreu aqui em Santa Catarina ${ }^{45}$. O Deputado Estadual, Pedro Uczai (PT-SC), enviou à Assembléia Legislativa o projeto de lei complementar n. ${ }^{\circ} 15 / 98$, dando nova redação ao $\S$ único do artigo 41, capítulo V, da lei complementar n. ${ }^{\circ} 170 / 98$ sobre o Sistema Estadual de Educação. O texto apresenta a seguinte redação: "A filosofia e a sociologia constituirão disciplina obrigatória do currículo do ensino médio". Após tramitação nas comissões de Justiça e Educação, Cultura e Desportos, e pronunciamento favorável à emenda, proferido pelo Conselho Estadual de Educação de Santa Catarina, o projeto foi aprovado por unanimidade, tanto em primeiro quanto em segundo turno, sendo sancionado pelo então governador Paulo Afonso Evangelista Vieira, no dia 21 de Dezembro de 1998, como lei n. ${ }^{\circ}$ 173/1998.

No Estado de Santa Catarina o projeto foi aprovado e sancionado e tal fato pode ser um aspecto relevante na mudança da estrutura curricular das escolas estaduais de ensino. Contudo, até o momento o caráter de obrigatoriedade da lei não garantiu a reintrodução da Filosofia nos currículos de todas as escolas. O desafio agora está em transformá-la em presença viva nos diversos cursos de ensino médio. E isso dependerá muito mais da organização dos professores que lecionam nas escolas, dos alunos que cursam a graduação, dos professores que fazem a formação inicial nas universidades, do que de vontade política dos órgãos estaduais competentes. Eis então o maior desafio: o de não deixar que esta emenda se torne lei morta.

43 Paulo Renato de Souza foi Ministro da Educação no período de 1995 a 2002.

44 Conforme "Despachos do presidente da República", mensagem n. ${ }^{\circ} 1.073$, de 8 de Outubro de 2001.

45 Estado situado na região sul do Brasil, cuja capital é Florianópolis. 
Alguns anos mais tarde, porém, os esforços históricos de professores e lideranças políticas tiveram seu momento de realização após a promulgação pelo Governo de Luiz Inácio Lula da Silva da lei n. ${ }^{\circ} 11.683$ de 2 de Junho de 2008, que torna as disciplinas de Filosofia e Sociologia obrigatórias no ensino médio. Tal medida estabeleceu uma nova redação para a Lei de Diretrizes e Bases da Educação, no seu artigo $36, \S 1^{\circ}$, inciso III, revogando-os e estabelecendo o inciso IV que estabelece a diretriz de que "serão incluídas a Filosofia e a Sociologia como disciplinas obrigatórias em todas as séries do Ensino Médio".

Com esta medida, quis o legislador estabelecer que as duas disciplinas componham obrigatoriamente todas as séries do currículo do ensino médio oferecido por escolas, sejam elas, públicas ou privadas. Além disso, de acordo com resolução do Presidente da Câmara de Educação Básica, Cesar Callegari, os prazos para implementação destes componentes curriculares terão os seguintes prazos:

a) início em 2009, com a inclusão obrigatória dos componentes curriculares Filosofia e Sociologia em, pelo menos, um dos anos do Ensino Médio, preferentemente a partir do primeiro ano do curso;

b) prosseguimento dessa inclusão ano a ano, até 2011, para os cursos de Ensino Médio de 3 anos de duração, e até 2012, para os cursos com duração de 4 anos. (BRASIL, 2008, p. 7)

Esta é uma nova realidade que estamos lidando no atual momento. O desafio está posto, pois a lei garante, mas os currículos são um campo em disputa e não se sabe exatamente como os Sistemas Estaduais de ensino público e as escolas privadas se comportarão para o cumprimento desta etapa de implantação das duas disciplinas.

\section{Considerações finais}

Tudo indica que naquele momento, início da década de 1970, a presença da filosofia parecia pouco rentável aos olhos dos tecnocratas, tratando-se de uma disciplina com pouca ou nenhuma "utilidade" para um país que havia feito uma opção clara por um projeto de desenvolvimento que atendesse as necessidades do mercado de trabalho. As raras exceções porventura existentes nada mais faziam do que confirmar a regra geral de um ensino acrítico e bem comportado. Além disso, tratava-se de formar "cidadãos", cujos princípios certamente não se desviassem dos ideais da segurança nacional. Obviamente, disciplinas como "Educação Moral e Cívica" e "Organização Social e Política do Brasil" eram bem mais qualificadas para essa função.

Na perspectiva acima levantada, embora com outro objetivo, KONDER (1981, p. 30) afirma que, 
"Considerada a filosofia tal como ela se desenvolveu a partir dos gregos, tal como ela veio existindo (e se modificando) ao longo de toda a história do Ocidente, a elaboração filosófica que se fez no Brasil até o recente surto de industrialização só pode nos inspirar desprezo; ou, no máximo, condescendência paternalista. Respeitados os parâmetros de uma certa tradição da história das ciências e disciplinas do saber".

Assim, parece-nos que o papel que o ensino de filosofia tem desempenhado ao longo da história cultural do país, era geralmente acrítico e ornamental. O papel propriamente subversivo atribuído à filosofia corresponde à parte da realidade, uma vez que o ensino de filosofia vigente no nível médio poderia se configurar como ameaça ao regime militar.

Em geral, a atividade filosófica na América Latina tem consistido em adotar e adequar doutrinas filosóficas européias com o objetivo de se justificar teórica e ideologicamente as iniciativas das nossas elites, como é o caso do Positivismo, que serviu para fortalecer um processo de modernização desde o final do século passado, ou então o caso de autores modernos europeus cujo pensamento foi empregado para fundamentar o processo de independência de alguns países em relação às metrópoles européias. Como se sabe, por muito tempo no Brasil, predominou o estudo da filosofia nos seminários católicos, dificultando o processo de laicização na atividade filosófica. Neste século, sobretudo até os anos 1960, o ensino de filosofia no II grau tem se caracterizado por um papel não muito diferente em relação a sua presença histórica no Brasil, ora como orientação dos estudos clássicos religiosos para pretendentes ao sacerdócio católico, ora como instrumentalização dos sistemas e governos conservadores. Nas últimas décadas, notadamente a partir de 1975, com a implantação de diversos cursos de pós-graduação, é que esse quadro começou a se modificar.

Mesmo assim, pouco se tem investido propriamente na perspectiva do filosofar, enquanto tentativa de solução dos problemas de forma criativa e original. Embora se afirme o papel crítico da filosofia na história do pensamento brasileiro, parece-nos que a filosofia em geral tem sido muito mais consciência da crise e muito menos projeto para sair da crise.

Assim, concluímos que as razões ideológicas ou políticas em geral, atribuídas como responsáveis pelo seu afastamento do II grau, não correspondem no todo com a realidade. O que nos parece mais possível é que naquele momento histórico, início dos anos de 1970, mesmo essa filosofia de caráter submisso e obediente parecia pouco rentável aos olhos dos tecnocratas, cuja disciplina teria pouca ou nenhuma utilidade para um país que, pelo menos pretensamente, havia feito uma opção clara por um tipo de desenvolvimento capitalista. 


\section{Referências}

ALVES, Dalton J. A Filosofia no ensino médio. São Paulo: Fapesp/Autores Associados, 2002.

BOSI, Alfredo. Cultura Brasileira. In: Durmeval T. Mendes (Coord.). Filosofia da Educação Brasileira. Rio de Janeiro: Civilização Brasileira, 1983.

BRASIL. DOCUMENTO DE BRASÍLIA. Sugestões de roteiros alternativos do ensino da Filosofia no II grau. Brasília, 18 nov. 1981. (mimeo)

Ministério da educação. Resolução n. ${ }^{\circ}$ 1, de 15 maio de maio de 2008.

CARTOLANO. Maria T. P. Filosofia no ensino de II grau. São Paulo: Cortez, 1985.

CHAUÍ, Marilena. Quem são os amigos da filosofia. Revista Discurso. São Paulo. N. ${ }^{\circ} 12$, p. 127-144, 1980.

Ideologias Autoritárias e Filosofia. Debates Filosóficos. N. ${ }^{\circ} 2$ SEAF/SBPC, Rio de Janeiro, 1981, pp. 31-56.

CUNHA, Luiz Antônio. Política Educacional no Brasil: A profissionalização do ensino médio. Rio de Janeiro: Eldorado, 1977.

GERMANO, José Willington. Estado Militar e Educação no Brasil. São Paulo: Cortez, 1993.

KONDER, Leandro. Filosofia e Conflito Ideológico no Brasil. In: Textos SEAF Curitiba-PR, ano 2 n.3 jan/dez 1981.

HORN, Geraldo B. Filosofia no Ensino Médio. In: Kuenzer, Acácia. (Org.) Ensino Médio. Construindo uma proposta para os que vivem do trabalho. São Paulo:Ç Cortez, 2000.

NÓBREGA, Odilso. Educação e Desenvolvimento. Rio de Janeiro: UFF, 1995, Dissertação de Mestrado.

PEGORARO, Olinto. A filosofia tenta provar que não está morta. Como? Voltando ao II grau. In: Jornal O Globo. Rio de Janeiro, p. 2, 25 de nov. 1977. Identidade da SEAF. Debates Filosóficos. N. ${ }^{\circ} 2$ SEAF/SBPC, Rio de Janeiro, 1981.

Política da Filosofia no Brasil. Zero Hora, Porto Alegre, p. 15, 06 outubro de 1979.

RODHEN, Valério. A Quem tem medo da filosofia? Revista Reflexão. PUCCAMP/SP, set./dez. 1980.

SEAF. A repintrodução e necessidade do ensino de Filosofia no currículo do

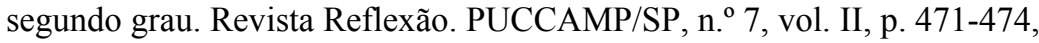
set. 1977.

Ata da Assembléia Geral de Constituição da Sociedade. Rio de Janeiro, 2 dez. 1976.

VALLS, Álvaro. Filósofos não querem algo imposto. Jornal Zero Hora, Porto alegre, p. 42, 3 abr. 1983.

VIEIRA, Evaldo. A República Brasileira - 1964-1985. São Paulo: Editora Moderna, 1985. 